\title{
Concepções do Alcoolismo na Atualidade: Pesquisas Hegemônicas, Avanços e Contradições
}

\author{
Renata Jacintho Siqueira Moraes ${ }^{1}$ \\ Sonia Mari Shima Barroco \\ Universidade Estadual de Maringá
}

\begin{abstract}
RESUMO - O texto resulta de uma revisão da literatura a respeito das concepções e formulações hegemônicas atuais sobre o alcoolismo, com vistas a identificarmos as principais proposições em relação à sua etiologia. Os resultados obtidos foram analisados segundo as formulações da saúde mental com base na epidemiologia crítica marxista, com objetivo de historicizar as concepções encontradas. Identificou-se que a etiologia bio-psico-social, com prevalência na determinação biológica, apresentouse como proposta recorrente para explicação do alcoolismo. Tal enfoque aponta a uma individualização do problema do abuso do álcool e a uma fragmentação das múltiplas determinações que compõem tal problema.
\end{abstract}

Palavras-chave: alcoolismo, etiologia, saúde mental, epidemiologia crítica marxista

\section{Current Conceptions of Alcoholism: Hegemonic Research, Advances and Contradictions}

\begin{abstract}
This text is the result of a literature review about the current conceptions and hegemonic formulations on alcoholism, in order to identify the principal propositions to its etiology. The obtained results were analyzed according to the mental health formulations based on a Marxist critical epidemiology, with the objective to place the identified concepts in a historical context. The results indicated that that the bio-psycho-social etiology, with prevalence in biological determination, has been proposed for recurrent explanation of alcoholism. This explanation demonstrates an individualization about alcohol abuse and a fragmentation of the multiple determinations that compose this problem.
\end{abstract}

Keywords: alcoholism, etiology, mental health, Marxist critique epidemiology

Diante do alarmante número de problemas sofridos pela população em decorrência do abuso de álcool e da grande incidência de seu consumo no Brasil e no mundo, objetivamos expor as concepções da Ciência Psicológica e Psiquiátrica sobre o alcoolismo no século XXI, analisá-las e discuti-las. Realizou-se um levantamento bibliográfico online no período entre 2010 e 2011 . Os resultados foram analisados a fim de compreender as formulações dos artigos acerca da etiologia proposta. Explicitaremos alguns questionamentos sobre as teorizações e proposições apresentadas, buscando suporte nos estudos da epidemiologia crítica marxista para compreender as raízes históricas das formulações científicas investigadas e suas implicações para a atuação do psicólogo na atualidade frente ao alcoolismo.

\section{Estado da arte das pesquisas sobre o alcoolismo}

A pesquisa bibliográfica online objetivou mapear o estado da arte referente ao nosso tema ${ }^{2}$. Foram tomados como base

1 Endereço para correspondência: Rua vinte e nove de junho, $\mathrm{n}^{\circ} 267$, Apto 308, Bloco 3, Bairro Bacacheri, Curitiba, PR, Brasil. CEP: 82515-396.

E-mail: remoraes.psicologia@gmail.com

2 Para a escolha dos artigos relevantes para o nosso levantamento, estabelecemos como critério utilizar somente trabalhos das áreas de Psicologia, Medicina, Enfermagem e Ciências Humanas, como antropologia, história e sociologia. Portanto, desconsideramos, para a efetividade do estudo, artigos que tratassem exclusivamente de pesquisas físico-químicas e farmacológicas. A pesquisa bibliográfica online foi realizada no período de julho de 2010 a janeiro de 2011. os bancos de dados Google Scholar (Google Acadêmico), do Centro Latino-Americano e do Caribe de Informação em Ciências da Saúde (Base Lilacs) e da Scientific Electronic Library Online (Scielo). Buscaram-se resumos e artigos em língua portuguesa considerando as seguintes palavras-chave em separado: alcoolismo, síndrome de dependência de álcool, uso de álcool, abuso de álcool, dependência de substâncias psicoativas e psicopatologia.

$\mathrm{Na}$ primeira etapa da pesquisa, foram encontrados, sob esses descritores, 537 artigos. Na segunda, houve a seleção dos materiais, por meio de leitura geral dos resumos, a partir da qual se observava a relevância do artigo para o estudo em questão. Resultaram 134 textos, os quais foram analisados segundo a explicação etiológica proposta (a forma como compreendem a causa, origem, do alcoolismo, ou seja, a teoria explicativa). As informações obtidas foram organizadas em figuras, para a melhor visualização, e serão discutidas na sequência. A Figura 1 refere-se à explicação para a etiologia do alcoolismo, segundo os artigos selecionados.

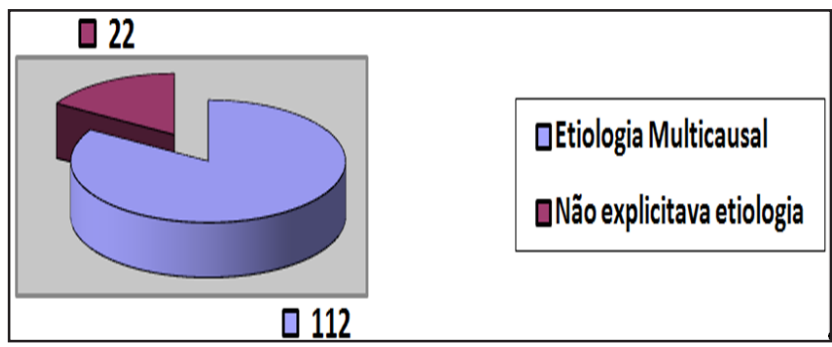

Figura 1. Etiologia. 
A etiologia é entendida como a determinação, causa ou origem do adoecimento (Pereira, 2004). Diz respeito também à teoria ou modelo explicativo em que se fundamentaram as pesquisas levantadas (Formigoni \& Monteiro, 1997; Mansur, 1991; Sonenreich, 1971). De acordo com diversos estudiosos do tema, como Sonenreich (1971), Mansur (1991), Formigoni e Monteiro (1997), Silveira, Julião e Niel (2006) e Dalgalarrondo (2008), as pesquisas acerca da determinação do alcoolismo não estão concluídas, motivo pelo qual ainda não existe uma resposta definitiva e consensulal para a questão apresentada. Apesar disso, os autores citados, entre outros, apontam que houve tentativas de responder a essa pergunta com base em algumas hipóteses levantadas, das quais as principais seriam as que relacionam o uso abusivo de álcool e a dependência a determinantes orgânicos, psicológicos e socioculturais (também chamados de ambientais).

Na pesquisa bibliográfica elaborada, os dados levantados convergem com os descritos pelos autores. Como demonstrado na Figura 1, dos 134 artigos analisados, 112 fizeram alusão a alguma explicação etiológica e ou teoria explicativa sobre o alcoolismo, utilizando como referência os fatores de determinação anteriormente citados (biológicos, psicológicos e ou sócio-culturais); e 22 não fizeram referência a nenhuma explicação etiológica. Trata-se de pesquisas de revisão bibliográfica ou de análise literária que não explicitavam uma concepção dos autores sobre a determinação do alcoolismo.

Ressaltamos que, dos 112 artigos analisados, todos apresentam uma compreensão multicausal (também chamada de multifatorial) para a explicação das causas do alcoolismo. Por isso, esses trabalhos foram agrupados com a nomenclatura Etiologia Multicausal. Isso significa que abarcaram no texto uma proposição que sugeria a causalidade do alcoolismo a partir de uma relação e composição de vários fatores. Frente a essa constatação, elencamos e organizamos, na Figura 2, os aspectos que foram citados e nomeamos essa explicação etiológica presente em todos os artigos analisados de biopsicossocial. Os determinantes relacionados foram: (a) biológicos (sexo, idade, fatores genéticos, marcadores orgânicos, como enzimas e taxas sanguíneas, comorbidades psiquiátricas e clínicas, psicofármacos), (b) psicológicos ou comportamentais (personalidade e identidade, processos subjetivos inconscientes, processos cognitivos, hábitos e repertórios comportamentais) e (c) sociais e ambientais (profissão, relações e condições de trabalho, família, etnia e religião, gênero, localidade urbano-geográfica e renda). Apesar de todos os 112 artigos terem abordado o uso e dependência do álcool a partir da multicausalidade, que aqui chamamos de biopsicossocial (como mostra a Figura 1), alguns trabalhos deram ênfase maior a um ou outro fator em sua pesquisa, como exposto na Figura 2.

O conceito biopsicossocial ou bio-psico-social indica uma associação de determinantes que podem levar ao adoecimento. Em outras palavras, significa a multifatorialidade ou multicausalidade da doença (Barata, 2005a, 2005b; Formigoni \& Monteiro, 1997; Mansur, 1991). Para exemplificar o modelo multicausal na explicação etiológica do alcoolismo, destacamos alguns trabalhos estudados. A publicação de Lima, Braga, Carvalho e Morais (2010), por exemplo, expressa essa ideia ao descrever o alcoolismo "como uma doença crônica; com fatores

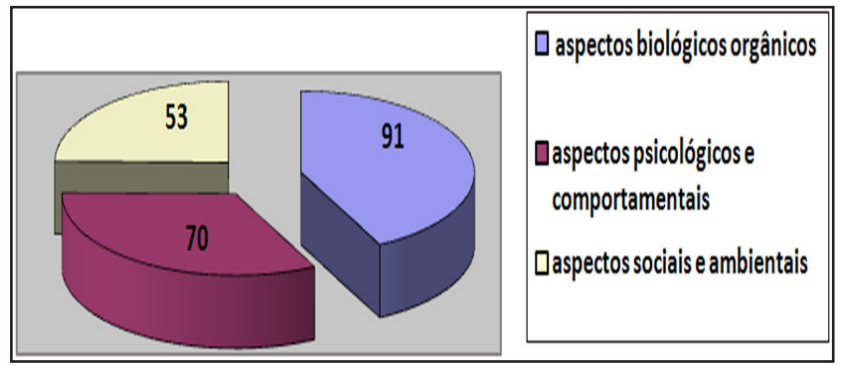

Figura 2. Etiologia multicausal

genéticos, psicossociais e ambientais influenciando seu desenvolvimento e suas manifestações" (p. 497). Para Ribeiro (2004), o alcoolismo é "influenciado por fatores biológicos, psicológicos e sociais” (p. 59).

De acordo com a literatura da área (Barata, 2005a, 2005b; Formigoni \& Mansur, 1991; Monteiro, 1997). Uma das características centrais dessa abordagem diz respeito à equivalência dos fatores biológicos, psicológicos e sociais na conformação do alcoolismo, não estabelecendo nenhuma espécie de hierarquia entre esses determinantes. Não obstante os trabalhos investigados relacionarem um rol de fatores na determinação do alcoolismo, eles não abordam da mesma forma a interação e relação dos aspectos listados, diversificação que está retratada na Figura 2.

Para a elaboração desta figura, foram relacionados, em cada categoria (aspectos biológicos orgânicos, aspectos psicológicos e comportamentais e aspectos sociais e ambientais), os determinantes que estavam em evidência em cada artigo analisado. As publicações, por considerarem múltiplas as causalidades, listaram uma série de aspectos que foram generalizados nas categorias descritas acima. Os elementos de causalidade que apareceram em cada agrupamento foram os seguintes: (a) 91 menções a aspectos orgânicos e biológicos: sexo, idade, fatores genéticos, marcadores orgânicos como enzimas e taxas sanguíneas, comorbidades psiquiátricas e clínicas, além de psicofármacos; (b) 70 menções a aspectos psicológicos ou comportamentais: personalidade e identidade, processos subjetivos inconscientes, processos cognitivos, hábitos e repertórios comportamentais; (c) 53 menções a aspectos sociais e ambientais: profissão, relações e condições de trabalho, família, além de aspectos relacionados à etnia e religião, gênero, localidade urbano-geográfica e renda. A quantidade de elementos mencionados excede o número de artigos analisados porque cada trabalho continha um ou mais determinantes para a explicação etiológica do alcoolismo. Esses elementos de causalidade estão combinados nos trabalhos analisados de diferentes formas, fazendo com que, nas publicações, constituíssem-se distintas composições do que seja a multicausalidade. Essas diferenciações explicitaram nos trabalhos a importância dada a esse ou àquele determinante, estabelecendo, assim, no quadro geral das causas, maior ênfase aos aspectos biológicos, seguidos dos psicológicos e comportamentais, e, por fim, dos sociais e ambientais.

Este fato nos exige a discussão dos aspectos mencionados para compreendermos a disparidade existente entre as explicações de causalidade. Para tal, explicaremos sinteticamente cada um desses componentes etiológicos, 
utilizando exemplos das publicações analisadas. Advertimos que essa separação dos agentes etiológicos foi elaborada a fim de melhor expor essas hipóteses de causalidade, mas, em rigor, os próprios artigos estudados reconhecem a interação de fatores etiológicos, o que leva a não existirem, de forma 'pura', aspectos biológicos, psicológicos ou sociais.

Os "aspectos orgânicos biológicos" foram notoriamente mais citados (91 menções) que os demais fatores nas publicações investigadas. Isso significa que, no bojo do que chamaram de multicausalidade, características inatas e orgânicas foram predominantemente pesquisados e analisados para se conhecer e/ou comprovar sua função na determinação do alcoolismo. Esses trabalhos, em sua maioria, trazem a ressalva de que a hipótese biologicista ainda não foi cientificamente comprovada, motivo pelo qual esses estudos ainda têm caráter experimental. A incerteza quanto à influência do organismo humano sobre o alcoolismo tem impulsionado pesquisadores a essas investigações, com base na ideia da necessidade de desenvolver padrões etiológicos objetivos (entendem objetivos como biológicos), o que, nessa visão, produziria diagnósticos e tratamentos mais eficazes (Rebello \& Carvalho, 2008).

Os trabalhos que corroboram a hipótese biológica diferenciam a dependência, a compulsão e a perda do controle na ingestão do álcool do simples beber ocasional (Formigoni \& Monteiro, 1997). Justificam esses "padrões" de consumo pela predisposição orgânica inata que os impulsionaria à ingestão excessiva de álcool. A perda do controle volitivo do beber estaria subordinada a mecanismos fisiológicos disparados pelo álcool, como: alterações no metabolismo celular, inibição dos "centros cerebrais de controle", ativação de circuitos neuronais específicos localizados no hipotálamo, entre outros (Di Pietro, 2006; Mansur, 1991; Niel \& Julião, 2006). No final do século XX e início do XXI, com avanço das pesquisas genéticas de mapeamento do genoma humano, as investigações acerca dos "genes do alcoolismo" ou de predisposições hereditárias a essa psicopatologia cresceram ainda mais na comunidade científica (Dal-Farra \& Prates, 2004; Formigoni \& Monteiro, 1997). Na atualidade, essas pesquisas de caráter biológico, pela predominância do paradigma da multifatorialidade flexibilizam a determinação estrita dos genes ou de padrões metabólicos no alcoolismo, e os colocam em relação ao ambiente em que o sujeito vive. Elencamos três trabalhos para exemplificar essa posição.

Dal-Fara e Prates (2004) apresentam que a etiologia do alcoolismo aponta para "um modelo multifatorial de herança, devido à influência de diferentes fatores genéticos e ambientais, bem como à interação dos mesmos" (p. 101). Os autores, apesar de considerarem o "ambiente" dentre os fatores etiológicos do alcoolismo, compreendem-no como uma herança, ou seja, como transmitido hereditariamente. Isso fica evidenciado na análise que fazem da influência da família (entendendo a família como um aspecto do ambiente), ao explicarem a ocorrência do alcoolismo entre familiares por fatores genéticos. Existiria, assim, uma subordinação do ambiente a aspectos biológicos - nesse caso, genéticos.

Rebello e Carvalho (2008) estudam os possíveis genes envolvidos com a susceptibilidade ou resistência ao alcoolismo. Mesmo afirmando que até o momento poucos genes foram comprovadamente associados à dependência de álcool, esses autores baseiam sua pesquisa na compreensão de que o ambiente apenas influencia o já estabelecido pelo código genético. Afirmam que "esses genes provavelmente interagem com os fatores ambientais, porque os experimentos genéticos sugerem que o meio ambiente tanto pode exacerbar quanto proteger a expressão genética de predisposição ao alcoolismo" (p. 164).

Deguti e Gonçalves (2000) buscam estudar os marcadores biológicos do alcoolismo, parâmetros físico-químicos do organismo do sujeito que auxiliariam o profissional de saúde a estabelecer um diagnóstico de padrões de consumo e de níveis de dependência de álcool. Propõem a verificação laboratorial de enzimas e alguns aspectos sanguíneos, para a constatação da situação presente do alcoolismo no sujeito. Para a verificação de uma possível tendência do sujeito a essa doença, sugerem o estudo da taxa de monoamino-oxidase plaquetária e de aspectos genéticos.

Por esse entendimento, mesmo incorporando fatores ambientais aos componentes genéticos e fisiológicos, essas pesquisas permanecem subsidiadas por uma concepção de homem que tem seu comportamento determinado por aspectos orgânicos, pelas leis da natureza. Esse ponto explicita uma contradição existente nesse rol de pesquisas, pois apesar da inclusão de fatores exógenos ao homem na investigação do alcoolismo, compactuando com a multicausalidade, ainda estabelecem uma hierarquia entre os determinantes, dando ênfase a um fator em detrimento dos demais.

O segundo aspecto mais citado na etiologia do alcoolismo foi o psicológico e comportamental, com 70 menções dentre os trabalhos investigados. Foram agrupadas nessa categoria explicações de causalidade que envolviam a personalidade e identidade, processos subjetivos inconscientes, sentimentos, processos cognitivos (pensamento, atenção, memória), hábitos e repertórios comportamentais. Em síntese, as diferentes concepções psicológicas acerca do alcoolismo presentes em nossa investigação situaram-se em duas grandes vertentes que levam em conta (a) aspectos da personalidade e (b) processos de aprendizagem.

Dentre as abordagens psicológicas citadas, a CognitivoComportamental foi a mais utilizada. Os artigos que corroboram essa teoria, mesmo não desconsiderando o papel dos aspectos biológicos na determinação do alcoolismo, incluem o estudo de processos como a memória, a consciência e principalmente as habilidades e os hábitos do sujeito (Aliane, Lourenço, \& Ronzani, 2006; Almeida \& Araújo, 2005; Oliveira, Andretta, Rigoni, \& Szupszynski, 2008). De forma geral, propõem a explicação da dependência do álcool como oriunda de um déficit no desenvolvimento de habilidades sociais dos sujeitos alcoolistas, ou também como um processo de aprendizagem. Nessa visão, o sujeito aprenderia a fazer uso dessa substância para lidar com problemas familiares, profissionais ou de outra ordem, sendo, para tanto, reforçado pelos efeitos físicos e de bem-estar psicológico momentâneo propiciados pelo álcool.

Outros aspectos psicológicos, como traços de personalidade, também são apontados com relação à etiologia do alcoolismo. Nos artigos estudados, são sugeridas condições como insegurança, imaturidade, passividade, instabilidade, introversão, impulsividade, ansiedade, fraqueza do ego e outras (Nascimento \& Justo, 2000; Niewiadomski, 2004). 
Assim como as abordagens organicistas, essas concepções que procuram indicativos ao alcoolismo na personalidade dos indivíduos, ainda não possuem dados conclusivos em suas pesquisas. Entretanto, supõem que as evidências da dependência de álcool devem ser encontradas nos sujeitos alcoolistas, seja em seu organismo ou em sua personalidade propensa a essa psicopatologia.

As pesquisas com esse viés, originadas em meados do século XX, foram impulsionadas pelo que especialistas chamam de concepção moralista do alcoolismo, ou seja, uma compreensão que o compreende como um desvio de caráter. A personalidade alcoolista representaria, assim, uma falha moral no sujeito, muitas vezes considerada inata (Formigoni \& Monteiro, 1997; Sonenreich, 1971). O advento das pesquisas genéticas teria tirado o foco dessa compreensão e dado maior visibilidade às pesquisas organicistas. Entretanto, como pudemos ver em nosso levantamento bibliográfico, mesmo com a prevalência das pesquisas multicausais, as explicações psicológicas ainda são vigentes, embora associadas a fatores biológicos e ambientais.

O trabalho de Aliane et al. (2006) compactua com a Teoria Cognitivo-Comportamental e expõe também uma visão multifatorial do alcoolismo. Considera a dependência resultante de "uma interação complexa entre os efeitos fisiológicos das substâncias psicoativas no cérebro e o que o usuário interpreta daquela situação, relacionando-a ao ambiente e consolidando como aprendizado" (p. 84). Caso a pessoa consuma dada substância e sinta um efeito psicoativo muito satisfatório ou reforçador, esse comportamento tende a repetir-se.

Assim, seja compreendendo os aspectos psicológicos e comportamentais como inatos ou como aprendidos, esse enfoque investiga no sujeito, em sua personalidade, cognição ou em sua conduta, as origens e traços do alcoolismo. Centra no indivíduo sua análise, assim como as pesquisas organicistas.

Por outro lado, existem também pesquisas que evidenciam em seu estudo etiológico os fatores sociais e ambientais, de modo que buscam também "fora" do indivíduo a causa de sua dependência. Como exposto na Figura 2, houve 53 menções a esses aspectos, referentes a questões como profissão, relações e condições de trabalho, família, etnia e religião, gênero, localidade urbano-geográfica e renda. Dessa listagem, a família e o trabalho foram respectivamente as determinações mais mencionadas.

Nessa perspectiva, o estudo sobre a influência da família na causalidade do alcoolismo - diferentemente do enfoque biológico, que analisava os fatores hereditários - investigava o papel dos hábitos e costumes da família e a qualidade das relações entre pais e filhos e das relações dos pais entre si na etiologia da dependência do álcool. A etnia e a religião foram pesquisadas também em relação à família, pois, na maioria dos trabalhos, eram tidas como componentes da cultura difundida pelos costumes familiares.

Souza, Jeronymo e Carvalho (2005) e Zanoti-Jeronymo e Carvalho (2005) apontam as relações familiares como fatores de proteção ou de risco para o alcoolismo, a depender de características da família. Entre as características consideradas relevantes, estão a existência ou não de respeito e cumplicidade entre os cônjuges e filhos, o nível de informação da família sobre os malefícios do álcool, o uso do álcool no meio familiar e os hábitos e costumes familiares referentes a essa questão.

Essas pesquisas também apontam fatores econômicos que envolvem a família, como a renda familiar e o local de moradia (periferias e regiões metropolitanas). Esse fator relaciona-se a outro aspecto indicado nos artigos: o trabalho. Sobre esse aspecto, as pesquisas apresentam, além do salário, as condições de trabalho e o estresse gerado nessa atividade como fatores de risco para o desenvolvimento do alcoolismo (Amaral \& Malbergier, 2004; Fonseca, 2007; Nascimento, Nascimento, \& Silva, 2007). Entre as demais causas do uso do álcool relativas ao trabalho estão: informalidade do trabalho, baixos salários, desgaste físico na atividade, jornada de trabalho, desemprego e outras.

A incidência do alcoolismo em jovens e adolescentes (estudantes do Ensino Médio e universitários) também foi citada nos artigos pesquisados. Os autores desses artigos atribuíram este uso ao contexto familiar, a relações de amizade e a hábitos - comportamentos comuns aos jovens - como ir a festas e bares (Silva, Malbergier, Stempliuk, \& Andrade, 2006; Soldera, Dalgalarrondo, Zanoti-Jeronymo \& Carvalho, 2005). Os artigos investigados mencionam os fatores sociais e ambientais na etiologia do alcoolismo como elementos de vulnerabilidade ou fator de risco, como dito acima. Isso significa que não propuseram esses aspectos como determinantes na dependência do álcool, mas como agravantes ou protetores a esse uso, a depender de outras causalidades, psicológicas e biológicas (Elbreder, Laranjeira, Siqueira \& Barbosa, 2008; Ribeiro, Rosa, \& Garcia, 2006). Nesse sentido, evidencia-se, assim como nos demais aspectos, o caráter biopsicosocial na multifatorialidade do alcoolismo.

\section{Discussão sobre as Concepções Hegemônicas: Os Avanços e as Contradições}

Partimos da compreensão de que as concepções sobre as doenças, seja a etiologia monocausal ou multicausal, devem ser apreendidas à luz dos momentos históricos em que foram desenvolvidas. Os modelos explicativos para o adoecimento humano foram desenvolvidos para responder às necessidades de explicação e intervenção nos processos de saúde e doença da população de suas épocas históricas (Barata, 2005a; 2005b; Breilh, 2006; Breilh \& Granda, 1989).

As concepções hegemônicas sobre o alcoolismo nos dias de hoje estão relacionadas às demandas objetivas de nosso tempo histórico, o que procuraremos explicar em nossa discussão. Contatamos em nosso levantamento bibliográfico que, de forma majoritária, as pesquisas sobre o alcoolismo baseiam-se em uma concepção etiológica multifatorial, ou seja, biopsicossocial, dos problemas advindos do uso de álcool.

A concepção multifatorial, ou multicausal, advém de uma proposta de superação do modelo etiológico monocausal da doença, também chamado de modelo biomédico ou organicista (Luz, 2011). A monocausalidade predominou em meados do século XIX, período de consolidação do modo de produção capitalista nos países da Europa Ocidental e 
EUA, bem como de impulsão às construções tecnológicas advindas das possibilidades criadas pela revolução industrial (Andery et al., 1994). A indústria e o comércio em ascensão consolidaram a concepção da nova classe dominante de compreender o mundo, e consequentemente o homem, com base na razão e nas leis gerais da natureza. Esses novos conhecimentos compuseram a chamada ciência moderna, que, em substituição às antigas ideias religiosas e feudais, explicam os indivíduos como sendo livres, demarcando a liberdade das amarras monárquicas e religiosas que dificultavam o livre comércio, e iguais, buscando estabelecer a igualdade da natureza biológica humana, em detrimento das diferenças entre as classes sociais acentuadas na época (Andery et al., 1994).

Para a ciência moderna, incluindo nesse rol a Medicina, o homem é concebido como uma extensão do mundo natural, sob os fundamentos da biologia, já conhecidos na época. Nas primeiras décadas do século XIX, devido ao grande número de mortes da população por doenças infecto-contagiosas, epidêmicas, e do advento das descobertas no campo da microbiologia, as doenças eram explicadas pelos agentes etiológicos conhecidos, os microorganismos, bactérias, vírus e fungos. Essa forma de compreensão das doenças foi chamada por especialistas de monocausal (Briz, 2009; Silva, 1985). O adoecimento era atribuído a um desajuste ou a uma falta de adaptação do organismo ao meio (meio ambiente, natureza). As intervenções consistiam na vacinação da população e no tratamento por medicamentos (Silva, 1985).

Não obstante, a teoria da monocausalidade tornou-se insuficiente para explicar a etiologia de doenças agravadas no período do Pós-Guerra (após 1945): as doenças crônicas, também chamadas de doenças "modernas" do século XX. Esse século foi marcado por duas grandes guerras mundiais, a de 1914-1918 e a de 1939-1945, que impulsionaram o estabelecimento de novos padrões de vida humana. De um lado, tinha-se destruição e graves problemas sociais e de saúde; por outro, a necessidade de reconstrução, o que fez alavancar novamente as economias e indústrias dos países envolvidos. Mudou, assim, o perfil patológico da população, com transformação das causas de adoecimento e morte (Laurell, 1982; Silva, 1985)

Contraditoriamente, em meio às guerras, desenvolveramse tecnologias de prevenção que tiveram sucesso na diminuição e no controle das doenças transmissíveis e infecciosas que adoeciam e matavam a população. Isso levou ao desenvolvimento de vacinas e à constituição de hábitos chamados de higiene, o que prolongou a vida da população e reduziu os quadros infecciosos (Laurell, 1982; Laurell \& Noriega, 1989).

Isso ocorreu concomitantemente ao desenvolvimento das chamadas crônicas e degenerativas. Condições de vida como a privação de alimentos e a insalubridade das condições de moradia e trabalho, foram intensificadas para a população empobrecida durante as guerras (Engels, 2008; Laurell \& Noriega, 1989). A necessidade de reconstruir os países destruídos também demandou um aumento da produção das indústrias, o que consequentemente impôs aos trabalhadores um ritmo acelerado de trabalho e de vida. Houve novamente um crescimento dos centros urbanos a fim de empregar a população nas fábricas e serviços destinados à produção e venda das mercadorias necessárias à retomada da vida no Pós-Guerra. Esse padrão de vida favoreceu esse novo conjunto de doenças, em decorrência das novas situações de moradia, alimentação, trabalho, etc. As doenças crônicas e degenerativas, como as coronárias, as hepáticas, as do sistema nervoso central e tumores malignos, passaram a ser, a partir da segunda metade do século $\mathrm{XX}$, as principais causas de morte e adoecimento da população, principalmente dos que estavam submetidos às piores condições: a classe trabalhadora (Breilh, 2006; Laurell \& Noriega, 1989). Assim, esse cenário do Pós-Segunda Guerra demandou dos países da Europa Ocidental e dos EUA a explicação para a desigualdade entre eles, bem como para a pobreza gerada, que trouxe à tona a miséria e as doenças que o modo de produção capitalista carrega consigo (Breilh, 2006; Laurell \& Noriega, 1989). As enfermidades crônicas e degenerativas não podiam mais ser compreendidas a partir da microbiologia, bactérias, vírus e fungos. Fazia-se necessária a incorporação na determinação dessas doenças de outros fatores, que não um agente biológico único (Barata, 2005a; 2005b; Briz, 2009; Laurell, 1982; Silva, 1985).

Os elementos incorporados na causalidade das patologias foram influenciados pelas formulações das ciências sociais, em ascensão nesse período (décadas iniciais do século XX), como a Antropologia, a Sociologia e a Psicologia (Barata, 2005a). Segundo estudiosos (Barata, 2005a, 2005b; Puttini et al., 2010), o ambiente foi incorporado à explicação das doenças, compondo o que a multifatorialidade chamava de tríade na determinação das patologias: o sujeito, o agente e o meio ambiente. Ainda explicado com termos da Biologia, o sujeito era entendido como um hospedeiro, que, com certas características naturais (seu aparato biológico), sofria influências do meio (o trabalho, a família, os hábitos, etc.) que favoreceriam ou dificultariam o desenvolvimento de certas doenças. Com base nessa explicação, as teorias da multifatorialidade foram chamadas em seu início (décadas de 20,30 e 40 do século XX) de Teorias Ecológicas. Nesse novo modelo, além do simples entendimento de desadaptação do sujeito ao seu meio, foram incorporados os impactos do meio sobre o corpo dos sujeitos como causa dos adoecimentos (Barata, 2005a; Puttini et al., 2010).

As mortes da população trabalhadora causadas relacionadas às novas condições patológicas demandaram das "grandes potências" medidas para reduzir e minimizar os óbitos, que significavam, no momento, a perda de mão de obra necessária ao trabalho nas indústrias (Laurell \& Noriega, 1989). Entre as medidas executadas, em 1948, foram criadas a Organização das Nações Unidas (ONU) e a Organização Mundial da Saúde (OMS). Entre outros intuitos gerais políticos e econômicos, tinham a obrigação de promover ações mundiais unificadas que auxiliassem a reconstrução dos países no Pós-Guerra. No campo da saúde, intentaram estabelecer políticas de sanitarismo em todos os países envolvidos, o que demandou um estudo acerca da etiologia das novas doenças, bem como um sistema unificado de classificação e descrição das novas enfermidades (Piccinini, 2006).

A constituição da OMS, em 1948, promulgou que "saúde é o estado de completo bem-estar físico, mental e social e não mera ausência de moléstia ou enfermidade" 
(WHO, 1948, p. 1). Essa concepção demarca, no campo das formulações científicas em saúde, a consolidação do pensamento multifatorial na causalidade das doenças. A OMS sugere a compreensão de saúde para além da ausência de enfermidades, o entendimento da doença não somente pela existência de um agente patológico, como, por exemplo, os microorganismos já conhecidos. Compreende-se a saúde ou a doença como um processo, uma construção a partir da história biológica, psicológica e social do sujeito (Briz, 2009; Puttini et al., 2010). Assim, com vistas à insuficiência do modelo monocausal, a inclusão de fatores psicológicos e sociais na compreensão da determinação das doenças em geral e do alcoolismo, ganhou ampla aceitação e foi inserida de forma a hegemonizar a compreensão, até os dias de hoje, sobre a causalidade das doenças, como pudemos perceber em nosso levantamento bibliográfico.

O modelo biopsicossocial pretende promover uma ampliação na compreensão das patologias, em substituição à causalidade reducionista advinda da teoria monocausal, biologicista. Sua ampla aceitação e inserção na comunidade científica se deu em muito a essa busca por abarcar o maior número possível de fatores na explicação da determinação das doenças, por parecer representar um investimento no estudo mais aprofundado e mais completo das enfermidades em todos os seus âmbitos e conformações (Werner, 2004).

Esse intento de ampliação da compreensão dos fatores etiológicos trouxe à multicausalidade um status de modelo completo, que pudesse responder às questões que o antigo modelo monocausal não pode mais abarcar (Silva, 1985). Começaram, assim, estudos sobre aspectos como: hábitos, relações sociais interpessoais e de gênero, especificidades culturais como a religião e etnias, entre outros, que eram negligenciados anteriormente pelo modelo biologicista. Alguns autores na área, tendo em vista a inclusão destes elementos na pesquisa, consideram a etiologia biopsicossocial um avanço no campo dos estudos sobre as doenças. Acreditam que as especificidades individuais e culturais, que eram antes desconsideradas na compreensão das causalidades das doenças, podem ser abarcadas no modelo multicausal.

Não obstante, em nosso levantamento, a multicausalidade não se apresentou de forma homogênea, ou seja, com igualdade entre os determinantes biológicos, psicológicos e sociais. Apesar da constatação da menção à teoria biopsicossocial na grande maioria dos trabalhos investigados, houve diferenças na ênfase dada aos determinantes, visto que constatamos a prevalência dos aspectos biológicos nos artigos analisados. Esses trabalhos, apesar de considerarem a multifatorialidade na determinação do alcoolismo, deram destaque aos aspectos orgânicos em suas investigações causais.

Mesmo reconhecendo a falta de comprovações suficientes para afirmarem a determinação biológica do alcoolismo, as pesquisas que trabalham com esta perspectiva o fazem com $\mathrm{o}$ intento de encontrar marcações objetivas que indiquem a causa do alcoolismo, e a objetividade neste caso diz respeito a indícios orgânicos somente. Este pensamento, apesar de próximo à concepção multifatorial, ainda estabelece estreitas relações com as concepções monocausais e biologicistas.

Silva (1985) afirma que a teoria da multicausalidade é, na verdade, uma expansão da monocausalidade, de modo que não representaria assim uma ruptura ou avanço em relação ao modelo antigo. "A aceitação da multicausalidade não pode ser considerada como um avanço teórico, mas sim como uma acomodação à teoria da unicausalidade, vigente na epidemiologia das doenças transmissíveis" (Silva, 1985, p. 381). O autor aponta esse problema não apenas pela prevalência dos enfoques biológicos nos estudos dos processos de saúde e doença, mas também por não ter havido uma alteração nos fundamentos filosóficos dessas pesquisas. A primazia do método empírico nos estudos sobre as causalidades, como as pesquisas que buscam os "vestígios" inatos do alcoolismo no organismo dos sujeitos, indica a permanência das concepções naturalistas e positivistas da ciência moderna (Breilh, 2006; Breilh \& Granda, 1989; Laurell, 1982; Silva, 1985; Werner, 2004). Ainda segundo Silva (1985), a dificuldade em considerar outros elementos no estudo da causalidade das doenças é resultado inclusive das limitações do próprio método empírico, que não consegue abarcar nem explicar os determinantes "não-biológicos das doenças" (p. 381). Dessa forma, fica evidente que, para lograrmos uma investigação que vá além das causalidades naturais, ou seja, que supere a pesquisa reducionista oferecida pela abordagem unicausal, é necessário o emprego de um método que seja capaz de conhecer a realidade para além de sua manifestação empírica imediata.

Apesar de termos identificado em nosso levantamento bibliográfico artigos que dão ênfase aos aspectos psicológicos e comportamentais bem como aos sociais e ambientais, estes não apresentaram uma abordagem do problema que os diferenciasse metodologicamente das pesquisas com enfoque biologicista. Os trabalhos que pesquisavam tanto aspectos da personalidade e cognitivos quanto hábitos e habilidades aprendidas na conformação do alcoolismo o faziam procurando identificar, no sujeito, em suas manifestações psicológicas, subjetivas ou de comportamento, evidências que demonstrassem seu papel causal no adoecimento em questão (Nascimento \& Justo, 2000; Niewiadomski, 2004). Desse modo, assim como as pesquisas organicistas, esses trabalhos citados têm subjacente aos seus estudos a hipótese de que as causas do alcoolismo podem ser encontradas nos indivíduos, seja em seu aparato biológico ou em seu psiquismo e comportamento.

Essa concepção, segundo Barata (2005a), Breilh (2006) e Laurell e Noriega (1989), demarca um entendimento ideológico do que seja o homem e as relações sociais. Conforme Laurell (1982), a utilização das características individuais como referência para a explicação das diferenças entre os homens, inclusive de problemas sociais, tem origem no bojo da ciência moderna, oriunda do processo de industrialização e consolidação do modo de produção capitalista no século XIX. Para os autores citados no início deste parágrafo, o enfoque individual dado às doenças oculta o caráter coletivo dos processos de saúde e adoecimento da população. Dessa forma, o problema não residiria no estudo dos aspectos biológicos e psicológicos das doenças, mas na supervalorização desses fatores e na negligência e desconsideração do adoecimento enquanto um processo que possui características dos grupos populacionais e das classes sociais, e não somente de indivíduos particulares. Para Barata (2005a), esse enfoque no sujeito acaba por 
responsabilizar as pessoas individualmente por sua doença e pelo restabelecimento de sua saúde, ao passo em que deixam de questionar as condições de vida, das relações sociais e de trabalho existentes em nosso modo de produção (Luz, 2011). Na realidade, o que deveríamos discutir são os impactos de nossa sociedade na vida dos sujeitos, as exigências e demandas do acelerado ritmo de vida e trabalho, a degradação das condições de moradia e transporte para a população trabalhadora nas cidades e a péssima qualidade das relações sociais, geralmente marcadas pela violência e insegurança, como afirma Luz (2011) em sua caracterização de nossa sociedade capitalista em tempos de crise política e econômica.

Esse aspecto relaciona-se intimamente com a ênfase que alguns artigos deram aos aspectos que chamamos de sociais e ambientais. Vimos, em nossa revisão bibliográfica, que a inclusão dos fatores sociais à compreensão da causalidade do alcoolismo é apresentada, na maioria dos casos, como fator de risco ou de proteção a uma condição já pré-estabelecida por aspectos biológicos ou psicológicos inatos ao sujeito. Isso significa que, apesar da inclusão dos aspectos que envolvem os sujeitos de forma coletiva, os estudos os colocam de forma subordinada aos demais (biológicos e sociais), mantendo-se assim a predominância de causalidades individuais e naturais do alcoolismo (Elbreder et al., 2008; Ribeiro et al., 2006).

Breilh (2006), Sato, Lacaz e Bernardo (2006) e Laurell (1982) chamam a atenção ainda para quais fatores sociais e ambientais são abordados majoritariamente pelas pesquisas multicausais. Apontam que existe uma supervalorização dos "estilos de vida", culturais, de hábitos, sem, contudo, explicarem a natureza social e coletiva desses costumes, tratando-os como se fossem simplesmente de livre escolha dos sujeitos. Afirmam que a multifatorialidade, apesar de incluir os aspectos sociais e ambientais, colocam-nos dependentes dos elementos individuais já pré-existentes, de modo a anular as diferenças sociais produzidas em nossa sociedade, transformando-as em adversidades fortuitas subjetivas ou orgânicas. Os autores em referência de crítica não discutem também a forma como se daria esta influência do convívio em família, das adversidades no trabalho, das relações pessoais, e outras. A utilização do termo biopsicossocial, por vezes, acaba parecendo um "jargão" acadêmico que não explica realmente a forma de interação dos fatores, representando uma somatória de elementos causais isolados: bio + psico+social.

Segundo Barata (2005a), parece haver na multicausalidade uma justaposição de determinantes. Apesar da pretensão de promover uma análise ampliada do processo de adoecimento, realiza contraditoriamente uma fragmentação do homem, em seu corpo, suas manifestações psicológicas e o mundo externo a sua volta. Apesar das críticas feitas à antiga teoria unicausal, a multicausalidade mantém os mesmos fundamentos reducionistas da formulação tradicional.

É importante referir também que a falta de uma compreensão sólida do processo de constituição do alcoolismo e de outros transtornos mentais levou diversos autores a negar completamente a possibilidade de determinar a causalidade das doenças (Breilh \& Granda, 1989; Silva, 1985). Em outras palavras, ante a dificuldade e complexidade dos transtornos mentais e de outras doenças "modernas", passou-se a discutir e afirmar a impossibilidade de conhecimento de quaisquer causas e determinantes, priorizando-se a descrição dos quadros de adoecimento, em substituição à explicação de sua etiologia (Laurell, 1982; Silva, 1985).

Essa posição teórica e metodológica frente às pesquisas no campo da saúde também geraram formas de intervenções psiquiátricas e psicológicas. O parâmetro da impossibilidade da ciência em apreender a realidade dos fatos, neste caso, do psiquismo humano em seu adoecimento, levou e leva a ações que tem o exclusivo objetivo de lidar com as consequências da doença, com a amenização e controle dos sintomas e não de suas causas (Laurell, 1982; Silva, 1985).

\section{Conclusões}

Vimos que a teoria biopsicossocial, apesar de pretensamente ampla e complexa na compreensão do alcoolismo, por vezes, acaba reduzindo-se aos mesmos parâmetros das teorias unicausais, no enfoque individual do sujeito e na descrição dos sinais e sintomas. A mera justaposição de fatores, fragmentando o homem em suas esferas biológica, psicológica e social, como se estas fossem partes separadas do "quebra-cabeça" humano, não contribui para o avanço nas explicações do alcoolismo, tampouco para seu enfrentamento. Propomos, assim, que alcoolismo seja compreendido como uma produção humana, analisado em suas manifestações coletivas e individuais, buscando a compreensão do homem enquanto uma totalidade, o que significa entendê-lo como síntese de múltiplas determinações, e não como uma justaposição de elementos que se combinam na conformação do homem e de seu adoecimento.

Com relação à etiologia, faz-se necessário entender que o homem, enquanto um ser histórico e social (Breilh, 2006; Laurell, 1982), não pode ser fragmentando em suas esferas biopsicossociais. O ser humano é uma totalidade que encerra em si a história humana natural e social, de forma indissolúvel e em intrínseca relação. Para além da etiologia do alcoolismo, é preciso conhecermos a gênese e desenvolvimento do homem e de seu psiquismo, não o reduzindo, assim, à condição de alcoolista e ignorando todas as possibilidades e potencialidades presentes no sujeito. Isso significa que, para além da busca de causas e determinações dessa psicopatologia, devemos conhecer o homem em sua totalidade, como produto histórico e múltiplas determinações, reposicionando o fator biológico ante o cultural. Por esse entendimento, a etiologia do alcoolismo deve ser compreendida através da historicidade do constituído no momento presente, na histórica individual do sujeito em relação com a história da humanidade, da coletividade humana. Para isso, não é suficiente analisarmos somente os aspectos orgânicos do sujeito, seus mecanismos cognitivos, de personalidade, e suas relações familiares e sociais, é necessário buscarmos entender, além dessa manifestação presente e imediata, o alcoolismo enquanto um processo, uma síntese constituída da história de vida deste sujeito, que por sua vez está encarnada na história das produções humanas e de suas relações sociais dela decorrente.

À luz da história, é possível conhecermos os alicerces da constituição da vida dos homens, bem como dos processos de 
saúde e doença desenvolvidos. A análise dos fatos enquanto explicativos em si mesmos, fenômenos imediatos, leva-nos à permanente repetição, sem que avancemos, como vimos nas limitações das teorias multifatoriais calcadas nos mesmos princípios do antigo modelo unicausal que pretende superar.

\section{Referências}

Aliane, P. P., Lourenço, L. M., \& Ronzani, T. M. (2006). Estudo comparativo das habilidades sociais de dependentes de não dependentes de álcool. Revista Psicologia em Estudo, 11(1), 83-88.

Almeida, S. C., \& Araújo, S. B. (2005). Avaliação da efetividade do relaxamento na variação dos sintomas da ansiedade e da fissura em pacientes em tratamento de alcoolismo. Boletim da Saúde, 19(2), 135-142.

Amaral, R. A., \& Malbergier, A. (2004). Avaliação de instrumento de detecção de problemas relacionados ao uso do álcool (CAGE) entre trabalhadores da Prefeitura do Campus da Universidade de São Paulo (USP) - Campus Capital. Revista Brasileira de Psiquiatria, 26(3),156-163.

Barata, R. B. (2005a). Epidemiologia social. Revista Brasileira de Epidemiologia, 8(1), 7-17.

Barata, R. B. (2005b). Abordagens sociais, culturais e comportamentais em doenças endêmicas. Revista Com Ciência. Recuperado em 01 de agosto, de 2011 de http://www. comciencia.br/reportagens/2005/06/08.shtml

Breilh, J. (2006). Epidemiologia Crítica: Ciência emancipadora e interculturalidade. Rio de Janeiro: Fio Cruz.

Breilh, J., \& Granda, E. (1989). Saúde na sociedade: Guia pedagógico sobre um novo enfoque do método epidemiológico. São Paulo: Cortez.

Dal-Farra, R. A., \& Prates, E. J. (2004). A psicologia face aos novos progressos da genética humana. Revista Psicologia Ciência e Profissão, 24(1), 94-107.

Dalgalarrondo, P. (2008). Psicopatologia e semiótica dos transtornos mentais. Porto Alegre: Artmed.

Deguti, M. M., \& Gonçalves, L. L. (2000). Marcadores biológicos do alcoolismo. Revista de Psiquiatria Clínica, 27(1), s/p. Recuperado em 27 de julho, 2011 de http:/hcnet.usp.br/ipq/ revista/vol27/n1/artigo27(5).htm

Di Pietro, M. C. (2006). Síndrome da Abstinência do Álcool. In D. X. Silveira \& F. G. Moreira (Orgs.), Panorama atual de drogas e dependências (pp. 148-151). São Paulo: Atheneu

Elbreder, M. F., Laranjeira, R., Siqueira, M. M., \& Barbosa, D. A. (2008). Perfil de mulheres usuários de álcool em ambulatório especializado em dependência química. Jornal Brasileiro de Psiquiatria, 57(1),9-15.

Fonseca, F. F. (2007). Conhecimentos e opiniões dos trabalhadores sobre o uso e abuso do álcool. Escola Anna Nery Revista Enfermagem, 11(4), 599-604.

Formigoni, M. L. O. S., \& Monteiro, M. G. (1997). A etiologia do alcoolismo. In Ramos, S. P. \& Bertolote, J. M. (Orgs.), Alcoolismo hoje (pp. 45-64). Porto Alegre: Artes Médicas.

Laurell, A. C. (1982). A saúde-doença como processo social. Revista Latinoamericana de Salud, 2, 7-25.
Laurell, A. C., \& Noriega, M. (1989). Processo de produção e saúde: Trabalho e desgaste operário. São Paulo: Hucitec.

Lima, H. P., Braga, V. A. B., Carvalho, L. V., \& Morais, A. C. O. (2010). Significados do feminino no discurso de alcoolistas e interface com a saúde mental. Revista Texto Contexto Enfermagem, 19(3), 496-503.

Luz, M. T. (2011). Especificidade da contribuição dos saberes e práticas das ciências sociais e humanas para a saúde. Saúde Sociedade São Paulo, 20(1), 22-31.

Mansur, J. (1991). O que é alcoolismo. São Paulo: Brasiliense.

Nascimento, E. C., \& Justo, J. S. (2000). Vidas errantes e alcoolismo: Uma questão social. Psicologia: Reflexão e Crítica, 13(3), 529-538

Nascimento, E. C., Nascimento, E., \& Silva, J. P. (2007). Uso de álcool e anfetaminas entre caminhoneiros de estrada. Revista de Saúde Pública, 41(2), 290-293.

Niel, M., \& Julião, A. M. (2006). Conceitos gerais, avaliação diagnóstica e complicações clínicas. In Silveira, D. X. \& Moreira, F. G. (Orgs.), Panorama atual de drogas $e$ dependências (pp. 135-141). São Paulo: Atheneu.

Niewiadomski, C. (2004). Violências e alcoolismo: Abordagem biográfica em alcoologia e hermenêutica do sujeito. Psicologia em Estudo, 9(3), 331-341.

Oliveira, M. S., Andretta, I., Rigoni, M. S., \& Szupszynski, K. P. R. (2008). A entrevista motivacional em alcoolistas: Um estudo longitudinal. Psicologia: Reflexão e Crítica, 21(2), 261-266

Pereira, S. D. (2004). Conceitos e definições da saúde e epidemiologia usados na Vigilância Sanitária. Centro de Vigilância Sanitária do Estado de São Paulo.

Rebello, A. S., \& Carvalho, M. G. C. (2008). Metodologia para o estudo do poliformismo do gene da enzima álcool desidrogenase. Revista de Ciência Médicas e Biológicas, $7(2), 163-168$.

Ribeiro, M. (2004). Organização de serviços para o tratamento da dependência do álcool. Revista Brasileira de Psiquiatria, 26(Supl.1), 59-62.

Ribeiro, D. B., Rosa, E. M., \& Garcia, M. L. T. (2006). Alcoolismo e família: Fugindo das simplificações. Revista Emancipação, 6(1), 189-204.

Sato, L., Lacaz, F. A. C., \& Bernardo, M. H. (2006). Psicologia e saúde do trabalhador: Práticas e intervenções na saúde pública de São Paulo. Estudos de Psicologia, 11(3), 281-288.

Silva, L. J. (1985). Considerações acerca dos fundamentos teóricos da explicação em epidemiologia. Revista de Saúde Pública, 19, 377-383.

Silva, L. V. E. R., Malbergier, A., Stempliuk, V. A. \& Andrade, A. G. (2006). Fatores associados ao consumo de álcool e drogas em estudantes universitários. Revista de Saúde Pública, 40(2), 280-288.

Silveira, D. X., Julião, A., \& Niel, M. (2006). Tratamento do alcoolismo: O acompanhamento psiquiátrico. In D. X. Silveira \& F. G. Moreira (Orgs.), Panorama atual de drogas e dependências (pp. 142-147). São Paulo: Atheneu.

Soldera, M. S., Dalgalarrondo, P., Filho, H. R. C., \& Silva, C. A. M. (2004). Uso pesado de álcool por estudantes dos ensinos fundamental e médio de escolas centrais e periféricas de Campinas (SP): prevalência e fatores associados. Revista Brasileira de Psiquiatria, 26(3),174-149. 
Sonenreich, C. (1971). Contribuição para o estudo da etiologia do alcoolismo. São Paulo: Revista dos Tribunais.

Souza, J., Jeronymo, D. V. Z., \& Carvalho, A. M. (2005). Maturidade Emocional e avaliação comportamental de crianças filhas de alcoolistas. Psicologia em Estudo, 10(2), 191-199.
World Health Organization (WHO). (1948). Constituição da Organização Mundial de Saúde. Conferencia Internacional da Saúde, New York. Recuperado em 01 de agosto, 2011, de http:// apps.who.int/gb/bd/PDF/bd47/EN/constitution-en.pdf

Zanoti-Jeronymo, D. V., \& Carvalho, A. M. P. (2005). Alcoolismo parental e suas repercussões criança e adolescentes: uma revisão bibliográfica. Revista eletrônica Saúde Mental álcool e Drogas, 1(2), 1-15. 